\title{
Development And Research of Gas Engine Multi-Communicated Model with Delay
}

\author{
${ }^{1}$ Igor Petrovich Balabanov, ${ }^{2}$ Ilnaz Ilgizovich Nabiullin, ${ }^{3}$ Olga Nikolaevna Balabanova \\ 1,2 Naberezhnye Chelny Institute (Branch), KFU / Higher School of Engineering / Department of Information \\ Technologies and Energy Systems / Department of Automation and Management \\ ${ }^{3}$ Naberezhnye Chelny Institute (Branch), KFU / Higher School of Economics and Law / Department of Economics / \\ Department of Economics of Enterprises and Organizations \\ IPBalabanov@kpfu.ru \\ ilnaznabiullin5k@gmail.com \\ ONBalabanova@kpfu.ru
}

Received: 21st August 2020, Accepted: 14th September 2020, Published: 31st October 2020

\begin{abstract}
This article presents the simulation model of a gas engine designed to determine the optimal tuning parameters. The modern market requires the increase of engine power and a simultaneous decrease of fuel consumption [21; 19; 8]. The third important parameter is environmental friendliness [19; 8]. Thanks to computer modeling of the internal combustion engine, these parameters can be balanced [8; 1; 28]. The article presents the mathematical model of a gas-fueled engine, as well as the computer model implemented in the MATLab environment. The simulation results were compared with the parameters of a real engine after the bench test. The object of the study was the KAMAZ 82060 gas engine with the capacity of 260 horsepower. The stand provided the version of the initial data. These are: effective power, fuel consumption per hour, temperature and pressure of the fresh charge at the inlet and the gas temperature in front of the turbine.

The simulation result showed the simulation model deviations of no more than $12 \%$. Thus, we can conclude that the developed computer model of the KAMAZ 82060 engine is quite accurate. In other words, we can conclude that this developed model of the KAMAZ 82060 engine can be used for other studies, or for reconfiguring the engine by changing the design parameters of the selected engine in the computer model.
\end{abstract}

\section{Keywords}

Computer Model, Engine, Truck, Gas Engine

\section{Introduction}

Currently, the use of various gases as a motor fuel for vehicles and autonomous power plants becomes more and more common $[21 ; 19 ; 8 ; 1]$. This is due to both economic and environmental factors: the cost of natural gas is 2 times lower than the cost of gasoline AI-92 on average, and associated oil - 40-60\% lower than the cost of natural gas; the use of gas fuel can significantly improve the environmental performance of an internal combustion engine, in particular, the content of harmful emissions in exhaust gases $[1 ; 28 ; 9]$.

Therefore, the use of a gas engine in trucks as the main power unit is relevant and necessary.

In connection with the above arguments, the purpose of this work is to develop a computer model of a commercial vehicle gas engine. To achieve this goal, a number of tasks must be completed. First, to develop a mathematical model of a truck gas engine [18]. Secondly, to develop a computer model of a truck gas engine $[20 ; 13 ; 17]$. Thirdly, check the obtained simulation results during bench tests.

\section{Methods}

Let us construct a mathematical model based on the calculations of irreversible thermodynamic processes using the method by V.I. Grinevetsky - E.K. Masing [2]. It is advisable to divide the model into subsystems in the order of the engine thermodynamic processes $[3 ; 4 ; 5]$. 


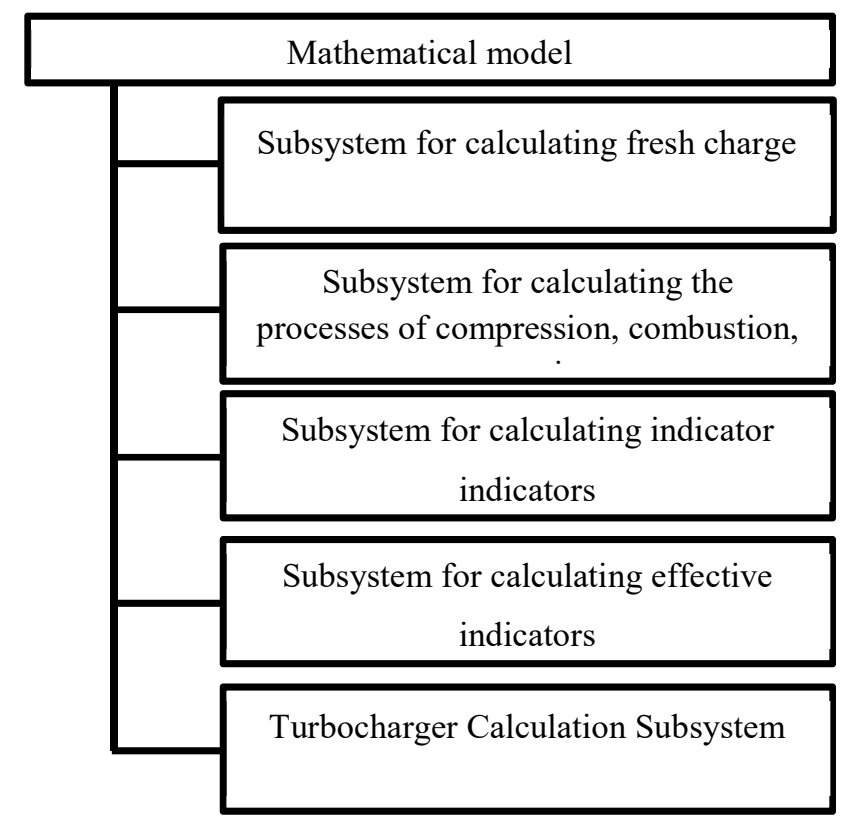

Figure 1: The Mathematical Model Scheme Based on the Calculation of Irreversible Thermodynamic Processes

The first subsystem includes the equations for calculating the fresh charge before starting the engine cylinders and it will be described according to the formulas $[6 ; 10]$ :

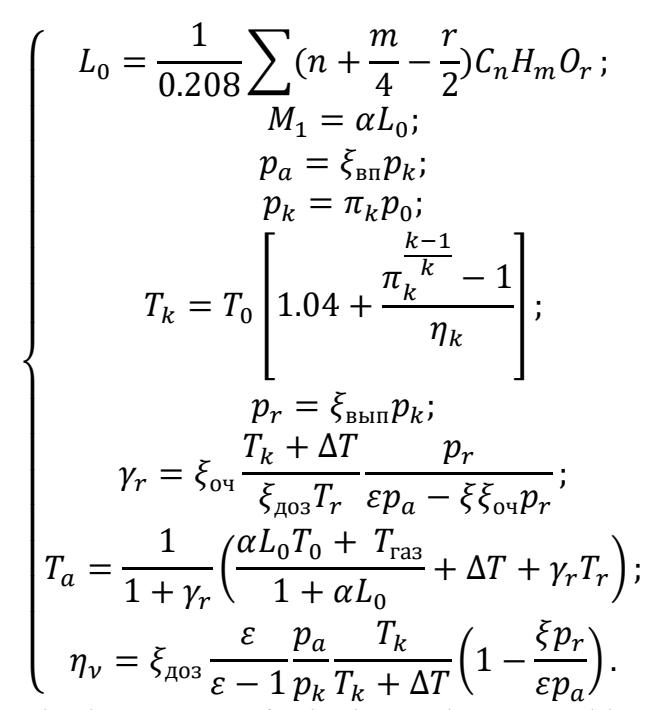

where $L_{0}$ - the theoretically required amount of air in moles or cubic meters for the combustion of 1 mole or $1 \mathrm{~m}^{3}$ of fuel (moles of air / moles of fuel or $\mathrm{m}^{3}$ of air $/ \mathrm{m}^{3}$ of fuel);

$\alpha$ - the excess air coefficient, taken equal to $\alpha=1.05$, to ensure reliable ignition of the mixture from a spark when they use hydrocarbon fuel and combustion efficiency;

$\xi_{\text {вп }}=0.8-$ the drag coefficient of the intake system, and $p_{k}-$ the intake pressure;

$\pi_{k}$ - the degree of pressure increase during the boost equal to $\pi_{k}=2.1, p_{0}-$ atmospheric air pressure equal to $p_{0}=0.10 \mathrm{MPa}$;

$T_{0}-$ air temperature equal to $T_{0}=298 \mathrm{~K}\left(25^{0} \mathrm{C}\right), k=1.4-$ adiabatic index, $\eta_{k}=0.71-$ adiabatic compressor efficiency;

$\xi_{\text {вып }}=0.9-$ the coefficient taking into account the resistance of the exhaust tract, depending on its design and operating factors;

$T_{r}=825 \mathrm{~K}$ - the temperature of the residual gases $\operatorname{Tr}$ has a slight effect on the filling of the cylinders with a fresh charge and is taken on the basis of experimental data; 
$\gamma_{r}$ - the coefficient of residual gases;

$\xi_{\text {оч }}-$ cleaning factor;

$\xi_{\text {доз }}=1.1-$ dosage factor;

$\Delta T=10-$ lowering the charge temperature in the charge air coolers;

$\xi=1.01-$ the ratio of the heat capacity of residual gases and fresh charge;

$\varepsilon=9-$ excess air ratio;

$\mathrm{R}$ - gas constant;

$9 T_{\text {газ }}=280 K$;

$\eta_{v}-$ the coefficient of filling the cylinders with fresh charge;

The second subsystem contains the equations for describing and calculating the processes of compression, combustion and expansion $[10 ; 15]$ :

$$
\left\{\begin{aligned}
p_{c} & =p_{a} \varepsilon n_{1} \\
T_{c} & =T_{a} \varepsilon^{n_{1}-1} \\
\mu_{\mathrm{sh} .} & =\frac{\mu_{0}+\gamma_{r}}{1+\gamma_{r}} \\
p_{z}=0.85 p_{z p} & =0.85\left(\mu_{\mathrm{sh} .} p_{c} \frac{T_{z}}{T_{c}}\right) \\
p_{b} & =\frac{p_{z}}{\varepsilon^{n_{2}}} \\
T_{b} & =\frac{T_{z}}{\varepsilon^{n_{2}-1}}
\end{aligned}\right.
$$

, where $p_{z p}$ - the calculated gas pressure at the end of combustion, and $T_{z}=2426 \mathrm{~K}-$ the temperature of the combustion products;

To calculate the indicator and effective values, the following systems of equations were drawn up: Indicators (indicative) of the cycle $[6 ; 22]$ :

$$
\left\{\begin{aligned}
& p_{i}=\varphi_{\text {п }} p_{i p} \\
& p_{i p}=\frac{p_{a} \varepsilon^{n_{1}}}{\varepsilon-1}\left[\frac{\lambda}{n_{2}-1}\left(1-\frac{1}{\varepsilon^{n_{2}-1}}\right)-\frac{1}{n_{1}-1}\left(1-\frac{1}{\varepsilon^{n_{1}-1}}\right)\right] \\
& \eta_{i}=\frac{p_{i} R M_{1} T_{k}}{22.4 p_{k} \eta_{\nu} H u} \\
& v_{i}=\frac{3600}{H u \eta_{i}} \\
& q_{i}=v_{i} H u \\
& N_{i}=\frac{p_{i} i V_{h} n}{30 \tau_{\text {д }}}
\end{aligned}\right.
$$

, where $p_{i}-$ specific work of the cycle;

$p_{i p}$ - average design indicator pressure;

$\varphi_{\Pi}=0.94-$ the coefficient of the diagram completeness;

$\eta_{i}$ - indicative efficiency;

$H u=35000 \frac{\text { кДж }}{\text { кг }}-$ the lowest heat of combustion;

$v_{i}$ - indicative gas consumption;

$q_{i}$ - indicative heat consumption;

$N_{i}$ - indicated power;

$\tau_{\text {д }}=4-$ engine stroke;

$i=8-$ number of cylinders;

$n-$ crankshaft rotation speed $\left(\min ^{-1}\right)$.

Effective cycle indicators $[6 ; 27]$ : 
$\eta_{\mathrm{M}}=0.8-$ mechanical efficiency;

$$
\left\{\begin{array}{c}
p_{e}=p_{i} \eta_{\mathrm{M}} ; \\
\eta_{e}=\eta_{\mathrm{M}} \eta_{i} ; \\
v_{e}=\frac{3600}{H u \eta_{e}} \\
q_{e}=\frac{3600}{\eta_{e}} \\
N_{e}=\frac{p_{e} i V_{h} n}{30 \tau_{\text {म }}} \\
M_{k . e}=\frac{9550 N_{e}}{n} \\
V_{t}=N_{e} v_{e}
\end{array}\right.
$$

where $p_{e}$ - the effective pressure;

$\eta_{e}$-effective efficiency;

$v_{e}$ - effective gas consumption;

$q_{e}-$ effective heat consumption;

$N_{e}$ - effective power;

$M_{k . e}$ - effective torque;

$V_{t}$ - gas consumption per hour.

To describe the operation of a turbocharger, the following system of equations has been compiled:

$$
\left\{\begin{array}{c}
G_{k}=\frac{V_{t} \alpha l_{0}}{3600} ; \\
G_{t}=\frac{V_{t}+0.98 G_{k}}{3600} ; \\
M_{k}=\frac{C_{p_{\mathrm{B} о з д} \times} G_{k}\left(T_{k}-T_{0}\right)}{w_{\mathrm{TK}}} ; \\
M_{T}=\frac{c_{p_{\text {ог }} \times} G_{T}\left(T_{b}-T_{T}\right)}{w_{\mathrm{TK}}} ; \\
T_{\mathrm{T}}=T_{b}\left(\frac{p_{r}}{p_{b}}\right)^{\frac{k-1}{k}} ; \\
w_{\mathrm{TK}}=\frac{1}{I_{\mathrm{TK}}} \int_{o}^{t}\left(M_{T}-M_{k}-M_{c}\right) d t .
\end{array}\right.
$$

, where $G_{k}$ - the second air flow rate through the compressor;

$G_{t}$ - the second gas flow rate through the compressor;

$M_{k}$ - compressor torque;

$M_{T}-$ turbine torque;

$T_{\mathrm{T}}-$ gas temperature in front of the turbine;

$k$ - polytrope exponent;

$w_{\mathrm{TK}}$ - angular speed of the TKR rotor;

$M_{c}=1.05-$ the moment of resistance arising as a result of the TKR rotor rotation;

$I_{\mathrm{TK}}-$ the moment of TKR rotor inertia.

To build a computer model of the KAMAZ 82060 engine with the capacity of 260 horsepower on the basis of the above-mentioned systems of equations for calculation of irreversible thermodynamic processes, "Simulink" program was chosen in the MatLab package.

First of all, you need to develop a TKR subsystem since it calculates the input parameters for the internal combustion engine, more precisely the temperature of the fresh charge before entering the supercharged cylinder $[27 ; 29 ; 7]$.

After building the TCR subsystem, it is necessary to build the model in the following order: intake process, residual gas parameters model, compression process, combustion process, expansion process, indicators and the effective cycle indicators.

A computer model of a truck gas engine built using the Simulink tool from the MatLab package is shown on Figure 2: 


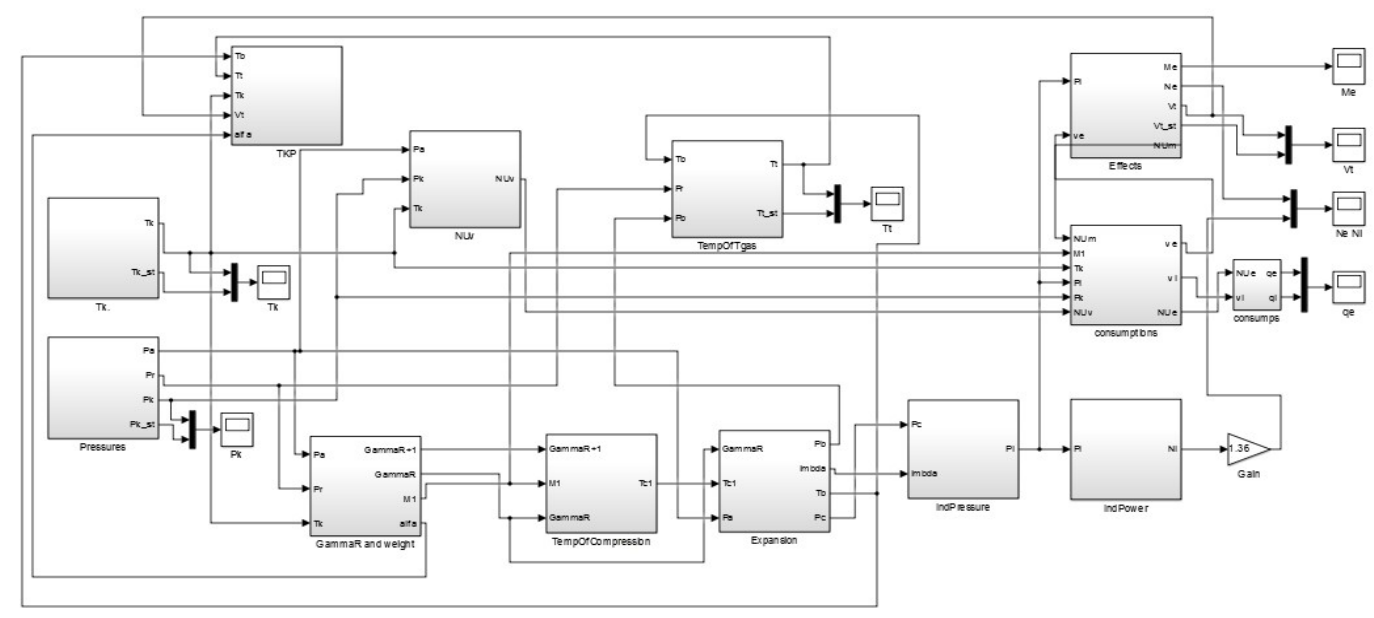

Figure 2: Computer Model of a Truck Gas Engine

The model consists of 13 subsystems, each of which calculates irreversible thermodynamic processes in accordance with the previously developed mathematical model $[12 ; 14]$.

1. NUv - this system calculates the filling ratio.

2. Expansion - this subsystem calculates gas temperature and pressure, gas temperature at the end of expansion, during expansion, the working mixture pressure during compression, as well as the rate of pressure increase.

3. TKR - this subsystem calculates the torques of the turbine and compressor, which are the part of the turbocharger.

4. Tk - this subsystem calculates the temperature of the fresh charge before entering the cylinder. The output parameters of the subsystem are the temperatures of the fresh charge before entering the cylinder after the simulation and the test result.

5. Pressures - the subsystem calculates the fresh charge pressure at the inlet $(\mathrm{Pk})$, the pressure of the fresh charge at the end of the intake ( $\mathrm{Pa}$ ) and the pressure of the residual gases (Pr). In this subsystem, the Pk_st parameter is implemented as an output parameter to compare the results of the fresh charge pressure calculation at the inlet and the bench test results.

6. GammaR and weight - the grammar and weight subsystem is used to calculate the amount of the working mixture (M1), the residual gas ratio (Gamer) and the excess air ratio (alfa).

7. $\mathrm{Tt}$ - calculates the gas temperature in front of the turbine.

8. TempOfCompession - the subsystem has calculated the temperature of the working mixture during compression.

9. IndPressure - This subsystem is used to calculate the indicator pressure (or specific duty cycle) Pi.

10. IndPower - this subsystem calculates the power indicator.

11. Consuptions - this subsystem calculates the gas consumption indicator:

12. Consumps - this subsystem calculates the indicator (qi) and effective (Ke) heat consumption.

13. Effects - this subsystem is necessary to calculate effective torque, power and fuel consumption per hour.

\section{Results and Discussion}

To assess the model reliability, a stand with the KAMAZ 82060 engine (the capacity of which makes 260 horsepower) was taken. In order to make the model to operate in the mode of the selected engine, it is necessary to select several values involved in the engine test as input parameters, namely: $\mathrm{n}$ - the number of the crankshaft revolutions; P0 - Atmospheric air pressure; $\mu 0$ - the coefficient of molecular change of the combustible mixture; $\alpha$ - the excess air coefficient.

The initial data values are shown in Table 1 . 
Table 1: Input Parameters

\begin{tabular}{|c|c|c|c|}
\hline $\mathrm{n}\left(\mathrm{min}^{-1}\right)$ & $\mathrm{P}_{0}(\mathrm{MPa})$ & $\mu_{0}$ & $\alpha$ \\
\hline 2200 & 0.1360 & 0.97 & 1.19 \\
\hline 2000 & 0.1350 & 0.85 & 1.18 \\
\hline 1800 & 0.1345 & 0.80 & 1.17 \\
\hline 1600 & 0.1340 & 0.75 & 1.16 \\
\hline 1400 & 0.1320 & 0.60 & 1.14 \\
\hline 1200 & 0.1300 & 0.57 & 1.14 \\
\hline 1000 & 0.1280 & 0.52 & 1.16 \\
\hline
\end{tabular}

One of the main indicators of engine performance is its power. Figure 3 shows the graphs of the indicator behavior (top line) and effective engine power (bottom line) depending on the crankshaft speed.

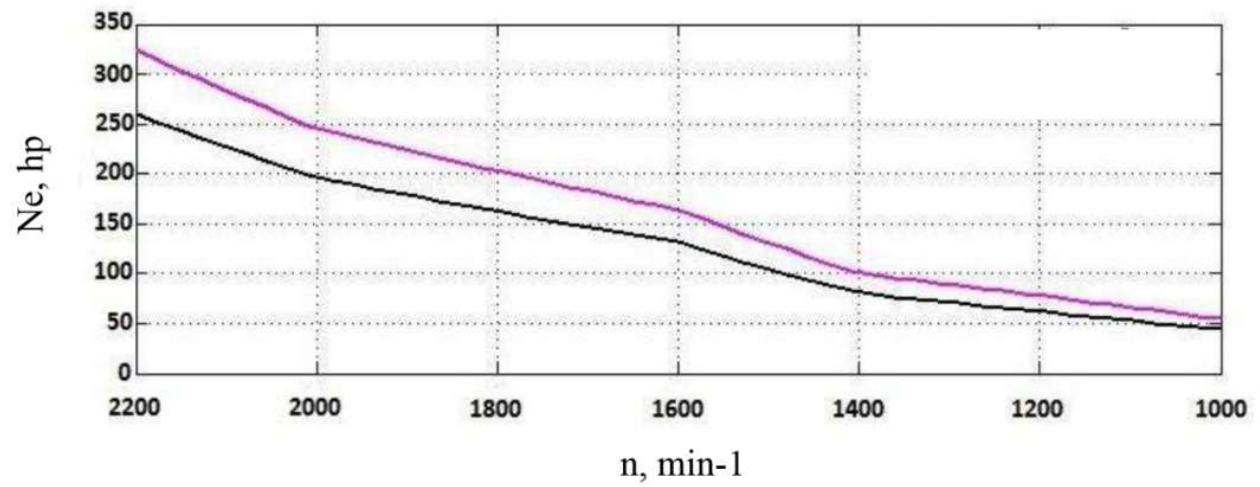

Figure 3: The Graph of the Indicative (Lower Line) and Effective Power (Upper Line) depending on the Crankshaft Speed.

As you can see from the graph 3, the stated effective motor power corresponds to the accuracy of $1 \%$. The graph also shows that the power in the model is higher than the effective power. This is due to the fact that indicative indicators are always better than effective mechanical losses in terms of efficiency.

The next, no less important indicator of engine performance is fuel consumption per hour. Fig. 4 shows the graphs of hourly cost changes for simulations and tests depending on the crankshaft speed.

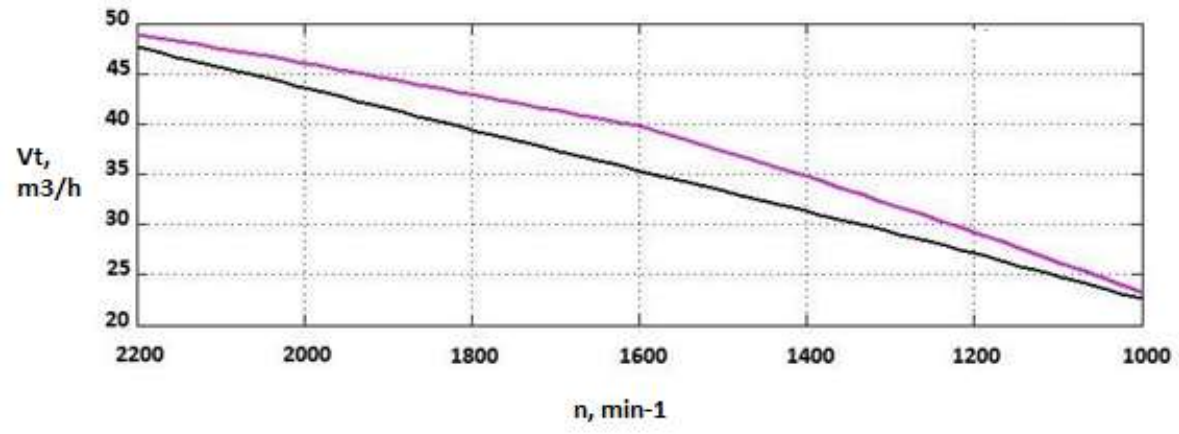

Figure 4: The Graph of Simulation (Top Line) and Test (Bottom Line) Hour Cost. The Graph shows that the Difference between Simulation and Testing is no more than $12 \%$.

Further, they compare the fresh charge pressure at the inlet (Figure 5), the fresh charge temperature (Figure 6), and the temperature of the gases in front of the turbine (Figure 7). 


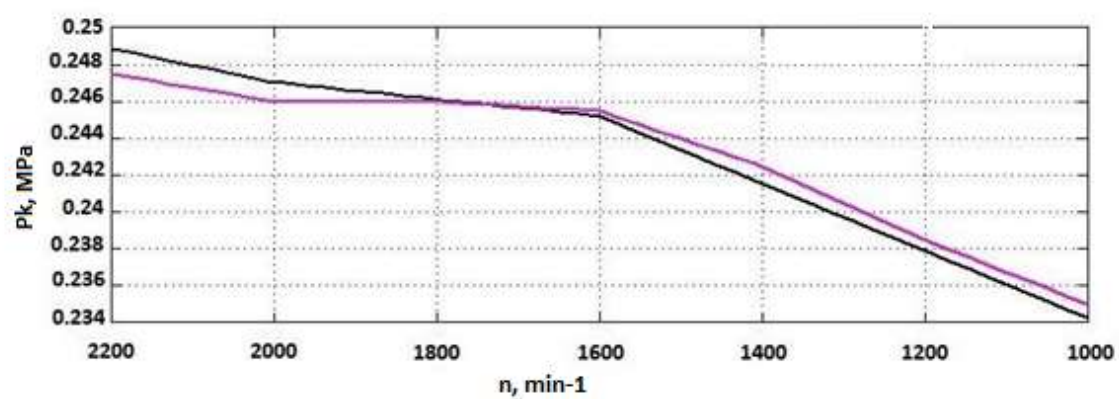

Figure 5: The Graphs of Fresh Charge Pressures at the Inlet

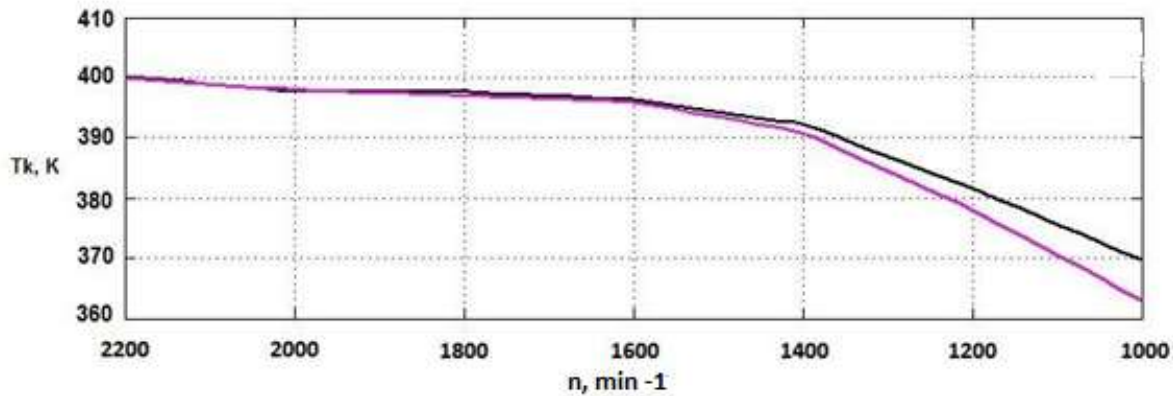

Figure 6: The Graphs of Fresh Charge Temperatures at the Inlet

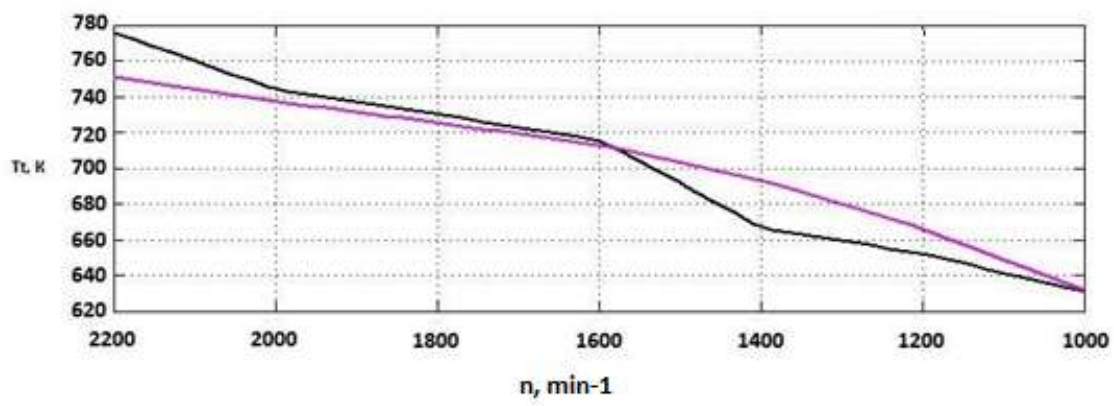

Figure 7: The Graphs of Gas Temperatures in Front of the Turbine

\section{Conclusion}

The simulation result showed the deviation of the simulation model which made no more than $12 \%$. Thus, we can conclude that the developed computer model of the KAMAZ 82060 engine is quite accurate. In other words, we can conclude that this developed model of the KAMAZ 82060 engine can be used for other studies, or to reconfigure the engine by changing the design parameters of the selected engine in the computer model.

The developed mathematical model made it possible to develop a simulation model. The resulting model will allow to carry out simulation tests for other engines of different power by changing some design parameters of the engine or changing the characteristics of the engine. Also, the computer model can be used for further research or for reconfiguring the engine by changing the design parameters of the selected engine in the computer model.

\section{References}

[1] Apelinsky, D.V., Shenderovsky, I.M., \& Yakhutl, D.R. (2012). Mathematical models of internal combustion engine working cycle with spark ignition and their numerical implementation. The Materials of the International Scientific and Technical Conference of the AAI "Automobile and Tractor Building in Russia: Development Priorities and Personnel Training", dedicated to the 145-th anniversary of MSTU "MAMI", 22 - 29. 
[2] Balabanov, I.P., \& Davletshin, F.F. (2018). Implementation of Iso 9001, Iso 14001, Iso 45001 Requirements with the Systems of Electronic Document Turnover. International Journal of Engineering and Technology(UAE), 7(4), 78-81. SCOPUS, www.scopus.com, doi:10.14419/ijet.v7i4.7.20388.

[3] Brecq, G., Bellettre, J., \& Tazerout, M. (2003). A New Indicator for Knock Detection in Gas SI Engines. International Journal of Thermal Sciences, 42(5), 523-532. SCOPUS, www.scopus.com, doi:10.1016/S1290-0729(02)00052-2.

[4] Candel, S. (2002). Combustion Dynamics and Control: Progress and Challenges. Proceedings of the Combustion Institute, 29(1), 1-28. SCOPUS, www.scopus.com, doi:10.1016/S1540-7489(02)800074.

[5] Chi, J.N., \& Dacosta, H.F.M. (2005). Modeling and Control of a Urea-Scr Aftertreatment System. SAE Technical Papers, SCOPUS, www.scopus.com, doi:10.4271/2005-01-0966.

[6] Elfasakhany, A. (2014). Experimental Study on Emissions and Performance of an Internal Combustion Engine Fueled with Gasoline and gasoline/n-Butanol Blends. Energy Conversion and Management, 88, 277-283. SCOPUS, www.scopus.com, doi:10.1016/j.enconman.2014.08.031.

[7] Gavarieva, K.N., Simonova, L.A., Pankratov, D.L., \& Gavariev, R.V. (2017). Development of expert systems for modeling of technological process of pressure casting on the basis of artificial intelligence. Paper presented at the IOP Conference Series: Materials Science and Engineering, 240(1) doi:10.1088/1757-899X/240/1/012019 Retrieved from www.scopus.com

[8] Gavrilov, A.A., Ignatov, M.S., \& Efros, V.V. (2002). Calculation of piston internal combustion engines: Part 1. Calculation of cycles and loads acting in the crank mechanism: Textbook / Vladim. state un - ty - Vladimir: - 142 p. ISBN 5-89368-347-1.

[9] Hack, G. (2003). Turbo engines and compressors: Handbook. - M.: LLLC Publishing house "Astrel - AST", - $351 \mathrm{p}$.

[10] Hjalmarsson, H. (1999). Efficient Tuning of Linear Multivariable Controllers using Iterative Feedback Tuning. International Journal of Adaptive Control and Signal Processing, 13(7): 553-572. SCOPUS, $\quad$ www.scopus.com, doi:10.1002/(SICI)1099-1115(199911)13:7<553::AID-ACS572>3.0.CO;2-

B.

[11] Kasjanov, S.V., \& Safarov, D.T. (2018). Mathematical modeling of the technological accuracy index deviation structure of the automobile parts. Paper presented at the IOP Conference Series: Materials Science and Engineering, 412(1) doi:10.1088/1757-899X/412/1/012039 Retrieved from www.scopus.com

[12] Khusainov, R.M., Yurasov, S.Y., \& Kazargel'dinov, R.R. (2017). Preparations for production in unigraphics NX software. Russian Engineering Research, 37(4), 363-366. doi:10.3103/S1068798X1704013X

[13] Konks, G.A., \& Lashko, V.A. (2006). Reciprocating internal combustion engines. Modern principles of design: Textbook. - Khabarovsk: The publishing house of Pacific State University, - $560 \mathrm{p}$.

[14] Krastyaninov, P.M., \& Khusainov, R.M. (2016). Selection of equipment for machining processing of parts using NX and TEAMCENTER programs. Paper presented at the IOP Conference Series: Materials Science and Engineering, 134(1) doi:10.1088/1757-899X/134/1/012041 Retrieved from www.scopus.com

[15] Lamaris, V.T., \& Hountalas, D.T. (2010). A General Purpose Diagnostic Technique for Marine Diesel Engines - Application on the Main Propulsion and Auxiliary Diesel Units of a Marine Vessel. Energy Conversion and Management, 51(4): 740-753. SCOPUS, www.scopus.com, doi:10.1016/j.enconman.2009.10.031.

[16] Lan, S., et al. (2018). A Dynamic Model for Thermoelectric Generator Applied to Vehicle Waste Heat Recovery. Applied Energy, 210, 327-338. SCOPUS, www.scopus.com, doi:10.1016/j.apenergy.2017.11.004.

[17] Lashko, V.A., \& Berdnik, A.N. (2006) Methodology for assessing the efficiency of gas turbine pressurization systems of combined internal combustion engines. Study guide - Khabarovsk: The publishing house of Pacific State University, - 118 p.

[18] Leno, V.E., Makushev, Yu.P., \& Shatalov, G.S. (1988). A.S. 1539353 USSR, F-2 B 29/04. Internal combustion engine. Declared on 04/01/1988; Published on 01.10.1989. No. 4401877. Bul. 4: 3 p.

[19] Lukanin, V.N., \& Morozov, K.A. (1995). Internal combustion engines. In 3 books. Book. 1. Theory of work processes. M.: Higher school, 368 p. 
[20] Makushev, Yu.P., Korneev, S.V., \& Ryndin, V.V. (2006). Engine pressurization units: Textbook. - Omsk: Publishing house SibADI: 58 p.

[21] Orlin, A.S., Kruglov, M.G., Vyrubov, D.N., Ivaschenko, N.A. et al. (1983). Internal combustion engines. In 4 books. Book 2. The theory of piston and combined engines. Textbook in the field of "Internal combustion engines" / Edited by A.S. Orlin, M.G. Kruglov. - 4th edition, revised and added. M., mechanical engineering, - $372 \mathrm{p}$.

[22] Ortenzi, F., et al. (2008). Experimental Tests of Blends of Hydrogen and Natural Gas in LightDuty Vehicles. International Journal of Hydrogen Energy, 33(12), 3225-3229. SCOPUS, www.scopus.com, doi:10.1016/j.ijhydene.2008.01.050.

[23] Safronov, N.N., Mingaleeva, L.B., Savin, I.A. (2018). Optimization of Charge Material Composition in Shs Process with Ferrosilide Fabrication from Gaseous Wastes of Metallurgical Production. Chernye Metally, 2: 53-59. SCOPUS, www.scopus.com.

[24] Salvat, O., Marez, P., Belot, G. (2000). Passenger Car Serial Application of a Particulate Filter System on a Common Rail Direct Injection Diesel Engine. SAE Technical Papers, SCOPUS, www.scopus.com, doi:10.4271/2000-01-0473.

[25] Shaparev, A.V., \& Savin, I.A. (2018). Influence of the State of the Contact Surfaces on the Formation of the Joint of Steel and Brass during Cold Cladding, 284 SSP, SCOPUS, www.scopus.com, doi:10.4028/www.scientific.net/SSP.284.319.

[26] Shaparev, A.V., \& Savin, I.A. (2017). Calculation of joint plastic deformation to form metal compound in cold condition doi:10.4028/www.scientific.net/SSP.265.313 Retrieved from www.scopus.com

[27] Squaiella, L.L.F., Martins, C.A., \& Lacava, P.T. (2013). Strategies for Emission Control in Diesel Engine to Meet Euro VI. Fuel, 104: 183-193. SCOPUS, www.scopus.com, doi:10.1016/j.fuel.2012.07.027.

[28] Vibe, I.I. (1962). New about the working cycle of engines. Moscow - Sverdlovsk: Mashgiz, 270 p.

[29] Wahlström, J., Eriksson, L., \& Nielsen, L. (2010). EGR-VGT Control and Tuning for Pumping Work Minimization and Emission Control. IEEE Transactions on Control Systems Technology, 18(4): 993-1003. SCOPUS, www.scopus.com, doi:10.1109/TCST.2009.2031473. 